\title{
Fine needle aspiration and core needle biopsy of metastatic malignancy of unknown primary site
}

\author{
Tarik M. Elsheikh ${ }^{1}$ - Jan F. Silverman ${ }^{2}$
}

Received: 20 July 2018 / Accepted: 22 July 2018 / Published online: 2 January 2019

(c) United States \& Canadian Academy of Pathology 2019

\begin{abstract}
Metastatic malignancies of unknown primary site (MUP) is the eighth most common form of malignancy, with an estimated $10-15 \%$ of oncology patients having a MUP. Fine needle aspiration cytology (FNA) and core needle biopsy (CNB) are often the first procedures utilized in the work-up of these cases and have a pivotal role for the diagnosis of metastases. There is an increasing emphasis on the precise classification of malignancy and determination of primary site of origin, utilizing smaller specimens. Recent available data suggest that there is a management benefit in identifying the primary site and/or specific cell lineage of MUP. In addition, the pathologists are asked to preserve the limited diagnostic material for potential molecular testing, as selected patients may benefit from targeted therapy. However, these tasks can become extremely challenging, especially if there is no previous history of malignancy, prior pathology is not available for review, or there is an unpredictable pattern of metastasis. In this review, we present a contemporary clinicopathologic approach to the workup of MUP that includes cytomorphology, ancillary studies, and clinicopathologic correlation. The cytohistologic subclassification of malignancies into specific cell lineages and/or morphologic categories is presented. Knowledge of the various patterns of metastasis to common and unusual sites can help narrow down the location of a primary site. The use of ancillary studies with particular emphasis on IHC utilizing an algorithmic approach and the role of molecular analysis as a diagnostic and theranotic test are also discussed. When the cell block and/or CNB lacks sufficient material for ancillary testing, the cell transfer technique may be utilized.
\end{abstract}

\section{Introduction}

There is an increasing emphasis on the accurate diagnosis and classification of metastatic malignancies utilizing smaller specimens and less invasive techniques, particularly core needle biopsy (CNB) and fine needle aspiration cytology (FNA). Providing an accurate diagnosis and determining a potential primary site of origin, utilizing small samples is especially important in the current era of expanding knowledge of tumor genomics and accompanying targeted therapies [1]. Therefore, in addition to

Tarik M. Elsheikh

elsheit@ccf.org

1 Department of Pathology, Pathology and Laboratory Medicine Institute, Cleveland Clinic, Cleveland, $\mathrm{OH}$, USA

2 Department of Pathology and Laboratory Medicine, Allegheny Health Network, Allegheny General Hospital, Pittsburgh, PA, USA providing a specific diagnosis, preservation of the limited diagnostic material for potential molecular and ancillary testing becomes crucial. Determining a primary site, however, can be especially challenging if there is no previous history of malignancy, prior pathology is not available for comparison, or there is an unpredictable pattern of metastasis [2].

In this review, we present a clinicopathologic approach to the work-up of metastases of unknown primary site (MUP), which includes cytohistologic morphology, ancillary studies and clinical patterns of metastasis (Table 1) [2, 3]. Recognition of subtle cytohistologic morphologic features of metastatic neoplasms and subclassifying them accordingly into various diagnostic categories, i.e., clear cell, spindle cell, small cell, large pleomorphic, etc., emphasizes differential diagnostic considerations and can give valuable clues to the location of the primary site. Familiarity with the variable clinical patterns of metastasis and primary malignancies most commonly associated with those metastatic sites is important in narrowing down the possible origins of these malignancies. The use of ancillary 
studies such as immunohistochemistry (IHC) and molecular testing can further help determine a cell lineage and a site of origin.

\section{Definition and work-up of MUP}

MUP is the eighth most common malignancy and constitutes $5-10 \%$ of all non-cutaneous malignancies [4]. This represents a higher incidence than non-Hodgkin lymphoma or ovarian cancer [5]. MUP patients have been traditionally treated with a non-selective empirical chemotherapy (platinum or taxane-based) and their prognosis has generally been poor, with an overall median survival of 4-12 months [6-11]. Favorable prognosis is seen, however, in subsets of patients with lymphoma, germ cell tumors, and thyroid cancer, and a fair response to combination therapy can be expected in metastatic breast, ovarian, and prostate cancers. On the other hand, metastatic gastrointestinal and urogenital carcinomas remain difficult to treat [12].

MUP is defined as a biopsy-confirmed malignancy in which the primary site remains unknown after a rigorous but limited initial clinical and radiographic evaluation [13].

Basic clinical evaluation usually consists of history and physical examination, laboratory studies including liver and renal function tests, chest X-ray, computed tomography (CT) of the abdomen and pelvis, mammography in women, and measurement of serum prostatic specific antigen in men [14]. Depending on the clinical situation, additional studies might include chest CT, breast ultrasonography, positron emission tomography scan, magnetic resonance imaging of the breast, and gastrointestinal endoscopy. Clinical work-up alone, however, may be associated with only $20 \%$ success rate in detecting a primary site. Studies have shown that utilizing pathologic evaluation, including performance of an extended panel of immunohistochemical stains, is more accurate (70\% success rate) and more cost effective than other clinical diagnostic modalities [15-17].

So what information does the oncologist need from a biopsy of MUP and what is the role of the pathologist? More recent studies have shown that optimal management may be aimed at specific organ sites which, therefore, relies heavily on identifying the primary site. Molecular studies may also recognize certain actionable mutations for targeted therapy, such as PDL-1, MSI, etc. Therefore, lending an accurate diagnosis is only one component of the pathologist's role in evaluating such specimens. Preservation of the limited diagnostic material for potential molecular and other ancillary testing is also crucial [1]. Adoption of an algorithmic approach to evaluating MUPs, including cytohistologic morphology, clinical parameters, and IHC, will help generate a practical differential diagnosis and arrive at an accurate determination of the primary site (Table 1) [1].
Table 1 Clinicopathologic approach to work-up of metastaes of unknown primary site
1.Clinical patterns of metastases
a. Common metastatic sites
b. Uncommon metastatic sites
2. Cytomorpholoic featrues
a. Specific cell lineage
b. Morphologic cell pattern
3. Ancillary studies
a. Immunohistochemistry, flow cytometry
b. Molecular testing

\section{Clinical patterns of metastases}

Although a previous history of malignancy and characteristic cytohistologic and IHC features are helpful in characterizing certain tumors, many metastatic malignancies lack a specific morphologic or IHC profile. The clinical patterns of metastasis usually parallel the blood or lymphatic drainage of the primary malignancy. Metastases, therefore, are usually related to the anatomic localization of the primary tumor and involve more common sites such as the lung, lymph nodes, and liver [3]. Cancer, however, may occasionally metastasize to unusual sites such as the breast, spleen, and pancreas, and this unpredictable pattern of metastases can pose diagnostic problems for clinicians and pathologists, which may lead to misdiagnosing the metastasis as a primary malignancy arising at that site [18]. Familiarity with the variable patterns of metastasis in conjunction with cytologic/histologic features and ancillary studies can facilitate arriving at an accurate diagnosis.

The initial sites of metastases usually involve lymphatic (lymph nodes) and venous pathways. Neoplasms with a regional lymphatic metastatic pattern include squamous cell carcinoma of the head and neck, cervical carcinoma, and melanoma. Neoplasms also metastasize via characteristic anatomic venous pathways [19]. The lung, for example is the initial venous metastatic site for carcinomas of the head and neck, bone, uterus, and kidney. On the other hand, carcinomas of the pancreas, stomach, and colon often go to the liver as their initial venous site of metastasis. Lymph nodes are by far the most common site harboring metastatic disease. Knowledge of exact location of the involved lymph node is of prime importance, as it can suggest the location of primary site. For example, metastases involving the cervical spinal region are often associated with nasopharynx primary, followed by hypopharynx and base of tongue, whereas submandibular lymph node metastases are usually derived from the anterior part of oral cavity and lips (Fig. 1) [20]. Other common sites of metastases, such as the lung, large bones, liver, brain, and adrenal glands, and their more likely primary origins are shown in Table 2 . 


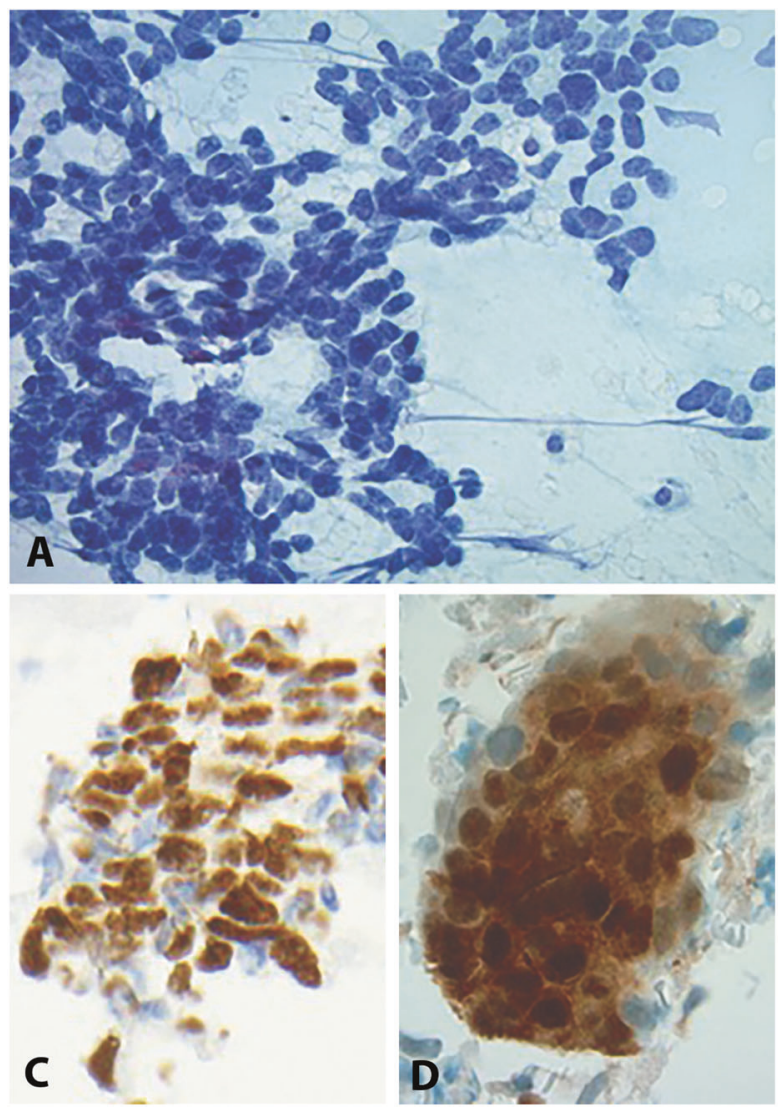

Fig. 1 Metastatic HPV-related squamous carcinoma. Fine needle aspiration biopsy of left upper cervical lymph node, 51-year-old male. The patient had no previous history of malignancy. Cytologic differential diagnosis included neuroendocrine carcinoma vs. basaloid squamous carcinoma. a, b Cohesive clusters of malignant cells with high nuclear-cytoplasmic ratios and occasional spindling.

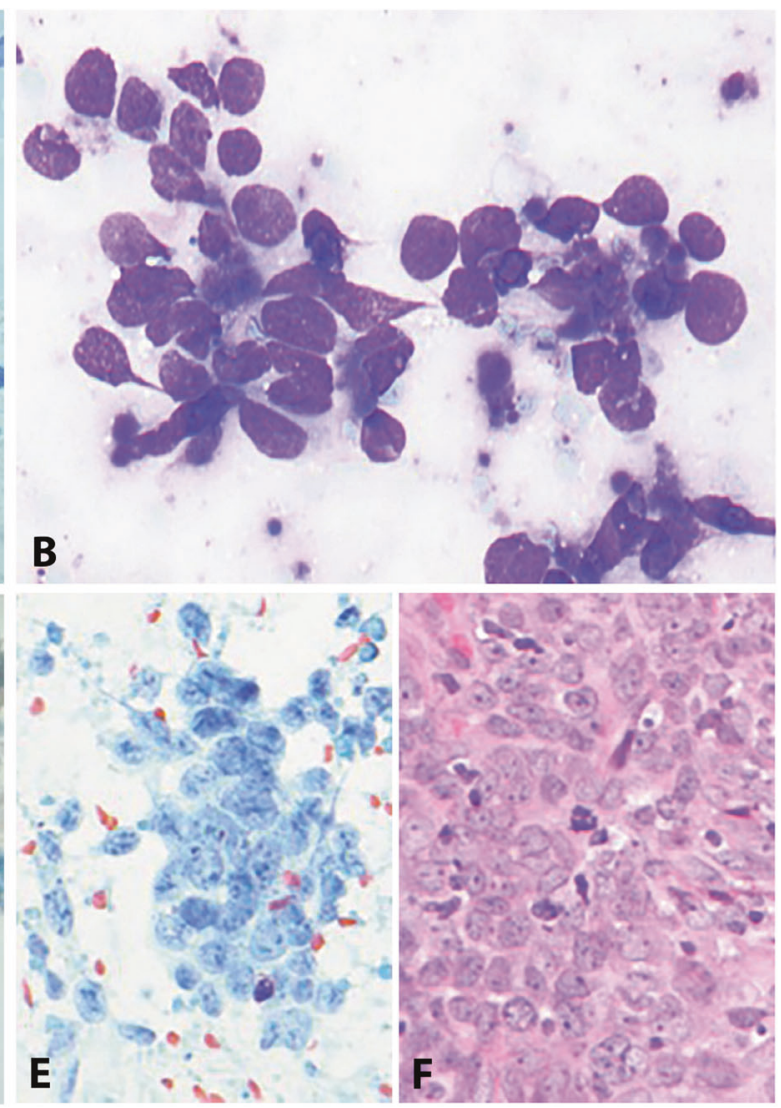

c-e Immunohistochemistry performed on cell block showed positive staining with p63 and p16, and negative staining with synaptophysin (TTF1 and chromogranin were also negative-not shown). $\mathbf{f}$ Based on combined cytologic and immunohistochemical findings, an oropharyngeal primary was favored. Follow-up revealed nonkeratinizing squamous carcinoma arising from left tonsil (H\&E stain)
Table 2 Common sites of metastases and probable primary origins

\begin{tabular}{ll}
\hline Site of metastasis & Probable primary origin \\
\hline Lymph nodes: & \\
Cervical & Head and neck, lung, melanoma, breast \\
Right supraclavicular & Lung, breast, lymphoma \\
Left supraclavicular & Lung, breast, cervix, prostate, lymphoma \\
Axillary & Breast, lung, arm, regional trunk, gastrointestinal \\
Inguinal & Melanoma, leg, cervix, vulva, trunk, anorectal, ovary, bladder, prostate \\
Lung & Breast, gastrointestinal, kidney, sarcoma, melanoma, prostate \\
Large bones & Prostate, breast, lung, kidney, thyroid \\
Liver & Gastrointestinal, breast, lung, lymphoma, genitourinary, sarcoma, \\
& melanoma \\
Adrenal gland & Lung, breast, kidney, gastrointestinal, liver, melanoma, lymphoma \\
Brain & Lung, breast, melanoma, gastrointestinal \\
Skin and subcutaneous tissue & Lung, breast, melanoma, head and neck, GIT \\
\hline
\end{tabular}

Subsequent widespread dissemination from initial metastatic sites is believed to occur via the arterial system to unusual sites such as the brain, small bones, and spleen [19]. Other uncommon metastatic sites include the breast, thyroid, pancreas, and kidney [2]. The most common primary malignancies metastasizing to these areas are shown in Table 3. In general, metastatic malignancy should always be suspected when the microscopic features appear to be 
unusual or has alien morphology for a garden variety primary malignancy arising within that site [18]. For example, a breast biopsy showing a pigmented malignant neoplasm or a small cell malignancy, should raise the diagnosis of metastatic melanoma or small cell carcinoma. A clear cell malignancy involving such organs as pancreas or thyroid should raise the suspicion of metastatic renal cell carcinoma

Table 3 Uncommon sites for metastases and probable primary origins

\begin{tabular}{ll}
\hline $\begin{array}{l}\text { Site of } \\
\text { metastasis }\end{array}$ & Probable primary origin \\
\hline $\begin{array}{c}\text { Breast } \\
\text { Female }\end{array}$ & $\begin{array}{l}\text { Contralateral breast, melanoma, lymphoma, lung, } \\
\text { ovary, sarcoma, gastrointestinal, genitourinary }\end{array}$ \\
Male & $\begin{array}{l}\text { Prostate, lymphoma, lung, bladder } \\
\text { Kidney, lung, breast, melanoma }\end{array}$ \\
Thyroid & $\begin{array}{l}\text { Lung, lymphoma, breast, kidney, liver, } \\
\text { gastrointestinal, melanoma }\end{array}$ \\
Kancreas & $\begin{array}{l}\text { Lung, breast, gastrointestinal, lymphoma, } \\
\text { melanoma }\end{array}$ \\
Small bones & $\begin{array}{l}\text { Lung, kidney, breast, gastrointestinal, melanoma } \\
\text { Spleen }\end{array}$ \\
\hline
\end{tabular}

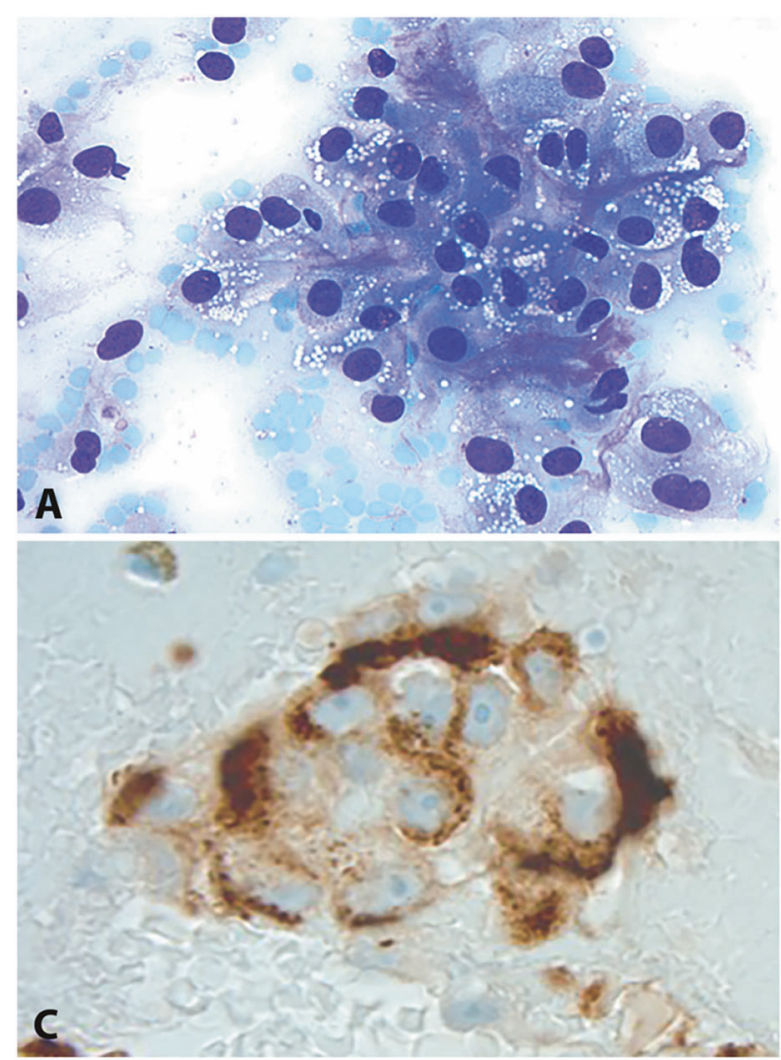

Fig. 2 Metastatic renal cell carcinoma to pancreas. Fine needle aspiration biopsy of 78-year-old male, with remote history of malignancy. a The neoplastic cells show abundant hypervacuolated cytoplasm, consistent with clear cell appearance, and thin fibrovascular strands (Diff Quik). b Cell block shows mixture of granular and clear
(Fig. 2). A metastatic poorly differentiated carcinoma or papillary carcinoma, however, may not be distinguished from a primary breast malignancy based on morphology alone, and ancillary studies would need to be utilized to arrive at a more specific diagnosis.

\section{Cytomorphologic features: specific cytohistologic types and pattern recognition}

In the work-up of a malignancy in a patient with or without a prior history of cancer, the differential diagnosis should include the distinction of a primary cancer from a MUP. The most common type of malignancy in both situations is adenocarcinoma. The diagnostic approach we recommend for the evaluation of metastatic as well as primary malignancies is to first attempt to determine the cell lineage based on the specific cytologic and histologic features that are present (Table 4). The primary cell lineages are adenocarcinoma, squamous or urothelial cell carcinoma, lymphoma, sarcoma, and melanoma (Fig. 3). If we cannot slot the malignancy into a specific cytohistologic lineage, then we assess the morphologic pattern by characterizing the cell type based on their cytoplasmic qualities or size into the

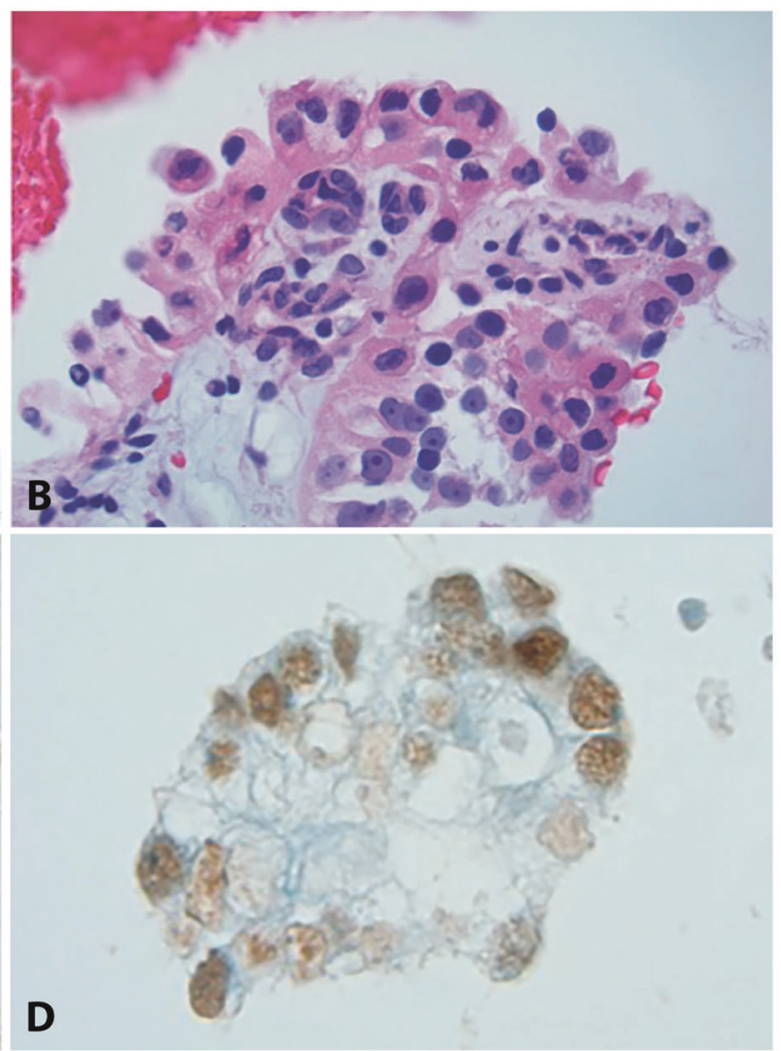

cell features and prominent nucleoli (H\&E stain). This clear cell morphology is unusual for a garden variety pancreatic primary, and metastases was suspected. d, e Immunohistochemistry performed on the cell block showed positive staining with renal cell antigen and PAX8, consistent with renal cell carcinoma 
following groups: (1) "small/round blue cells," (2) large/ polygonal cells, (3) spindle cells, (4) giant or pleomorphic cells and (5) oncocytic or granular cells, and [6] clear cells (Table 4 and Fig. 4) [2, 21-23].

Of the specific histologic types, adenocarcinoma is the most common type of malignancy, accounting for approximately $60 \%$ of the cases, followed by squamous cell carcinoma (approximately 5-10\%), undifferentiated and/or poorly differentiated carcinomas, small cell/neuroendocrine carcinomas, and melanoma. In the well-differentiated adenocarcinoma category, the most common unknown primaries include lung and pancreas, accounting for approximately $40 \%$ of the cases, followed by hepatocellular, colorectal, gastric, and renal cell carcinoma $[2,9]$.

Squamous cell carcinoma in the MUP syndrome most often originates in the upper aerodigestive tract and lung. Other primary sites include anogenital tract and esophagus. The presence of keratinization establishes the diagnosis, but

Table 4 Morphologic patterns of metastases

\begin{tabular}{ll}
\hline Specific cytohistologic cell lineage & Morphologic cell pattern/type \\
\hline -Adenocarcinoma & $\bullet$ Small cell \\
•Squamous carcinoma & $\bullet$ Oncocytic/granular \\
-Melanoma & $\bullet$ Clear cell \\
-Lymphoma & $\bullet$ Pleomorphic/giant cell \\
-Sarcoma & $\bullet$ Spindle cell \\
& $\bullet$ Polygonal/large cell \\
\hline
\end{tabular}

many of these metastatic squamous carcinomas lack keratinization [24]. The location of metastases can shed light on the primary site of origin, i.e., metastases to upper cervical, lower cervical, or inguinal lymph nodes most likely originated from head/neck, lung, or anorectal/genital primaries, respectively. With the increased prevalence of metastatic Human papilloma virus (HPV)-related squamous carcinoma, p16 IHC can be used as a surrogate marker for HPV (Fig. 1), but in-situ hybridization tests for high-risk HPV are more specific in confirming a metastatic HPV-related squamous carcinoma from the oropharynx or anogenital tract [25]. The presence of mixed glandular and squamous differentiation is associated with high-grade adenosquamous carcinoma, most commonly of lung and pancreatic origins.

Melanoma can metastasize to common and unusual sites and can mimic other malignancies or be occult or not readily apparent by history. Therefore, one needs always to think about the possibility of metastatic melanoma, whenever a MUP is encountered. Besides the characteristic morphologic features, such as the presence of intracytoplasmic melanin, other helpful diagnostic features include prominent nucleoli, intranuclear inclusions, and a moderate amount of cytoplasm [21, 26]. However, melanomas can have a variety of different cellular configurations, including pleomorphic, spindle, small cell, rhabdoid cells, and even cells with intracytoplasmic vacuoles (signet ring and balloon cell variants). A diagnostic pitfall for a false-positive diagnosis of metastatic melanoma is the presence of
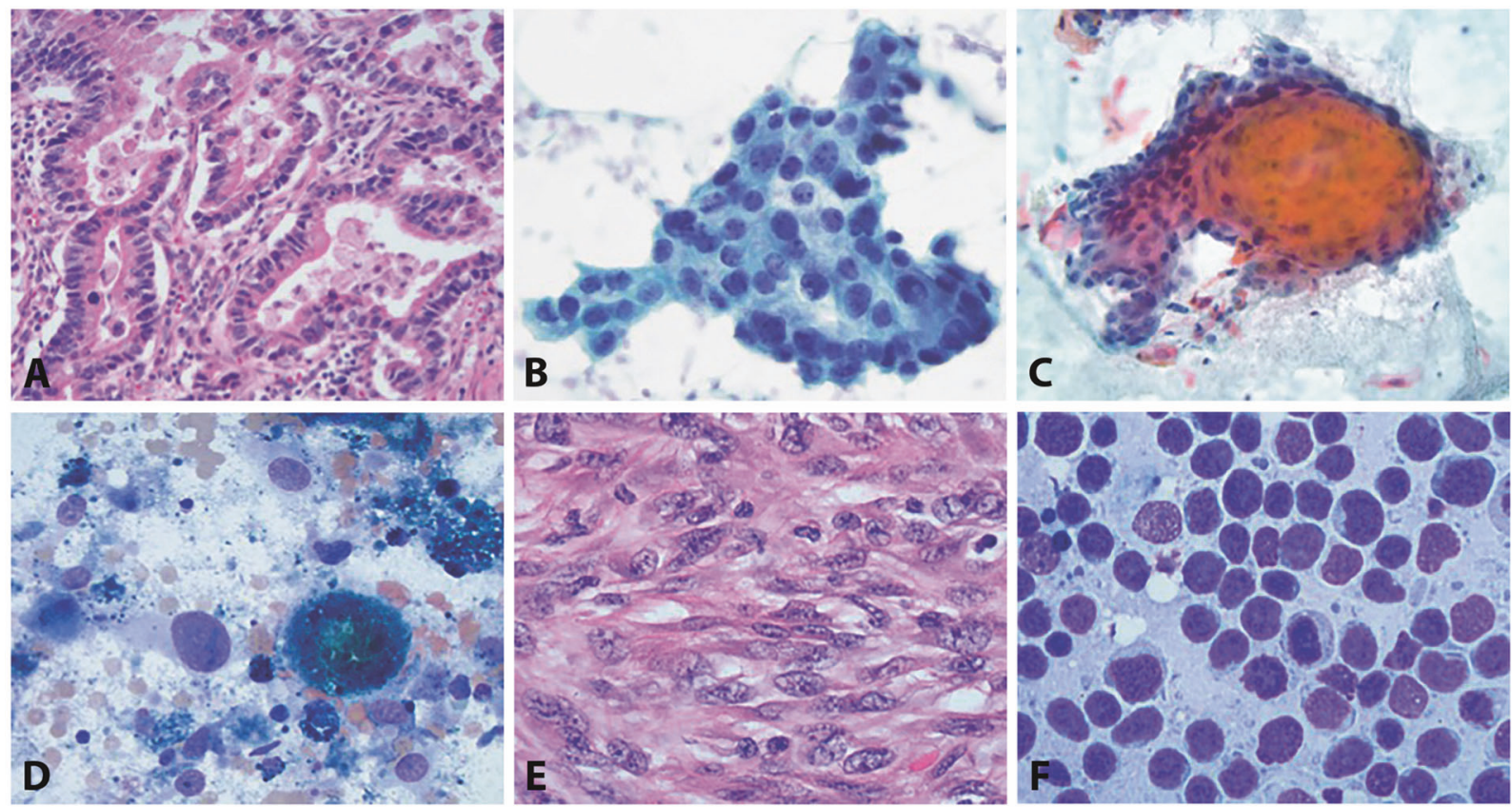

Fig. 3 Specific cell lineage (histologic types) of metastatic cancers. a Adenocarcinoma (H\&E stain). b Adenocarcinoma (Papanicolaou stain). c Squamous carcinoma with keratinization (Papanicolaou stain). d Melanoma with pigmentation (Diff Quik stain). e Sarcoma (H\&E stain). f Non-Hodgkin lymphoma (Diff Quik stain) 


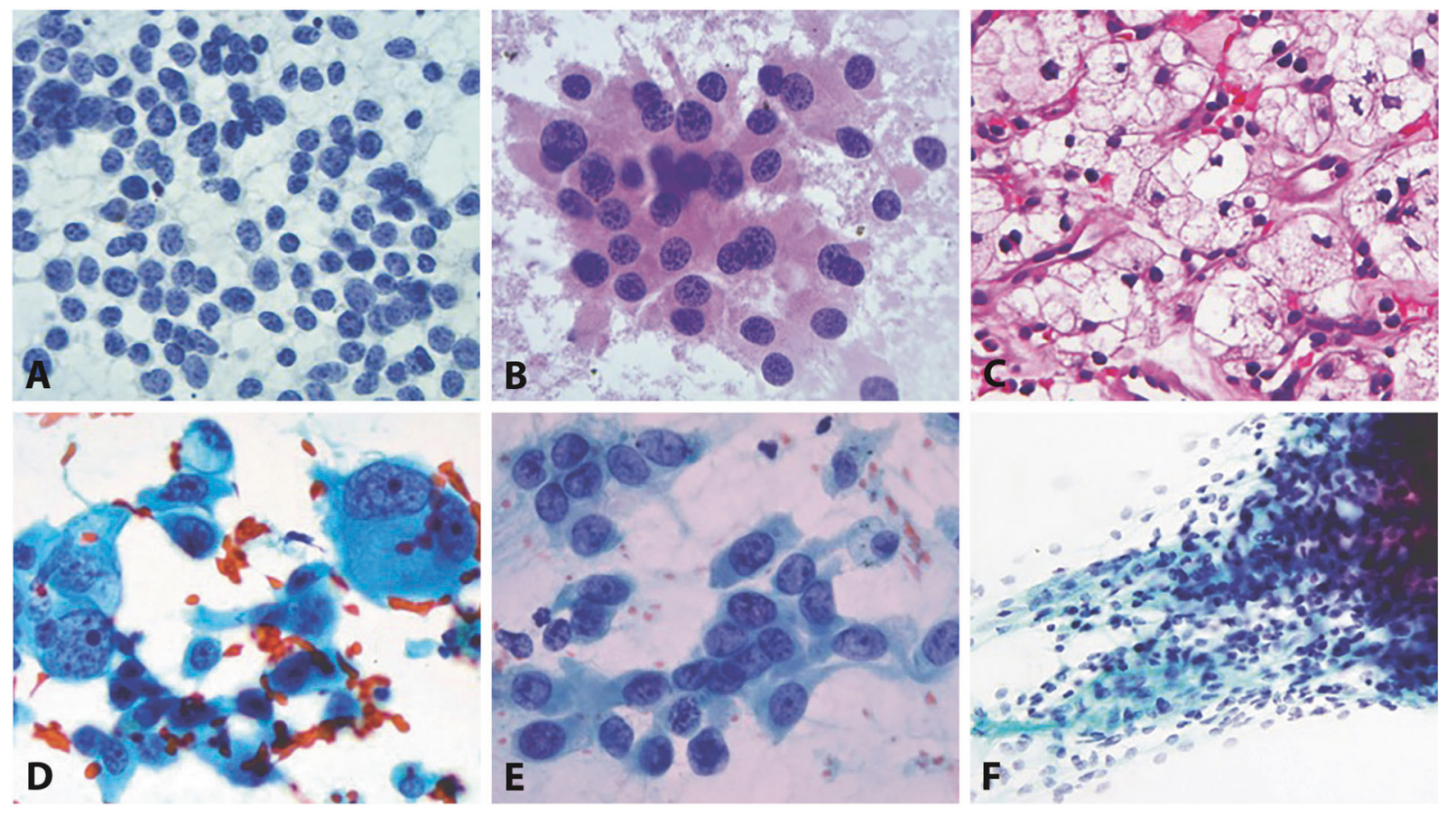

Fig. 4 Morphologic cell patterns. a Small cell (Papanicolaou stain). b Oncocytic/granular (Diff Quik stain). c Clear cell (H\&E stain). d Pleomorphic/giant cell (Papanicolaou stain). e Large cell/polygonal (Papanicolaou stain). f Spindle cell (Papanicolaou stain)

pigmented dendritic histiocytes in an aspirate from a lymph node draining a skin lesion.

A non-Hodgkin lymphoma can often be suspected due to the dissociative distribution pattern of the cells on the cytologic smears. The nuclei tend to be irregular and nucleoli can often be appreciated. One helpful feature for the diagnosis of lymphoma is the appreciation of so-called lymphoglandular bodies, which are stripped cytoplasmic fragments in the background of the smears, which can be seen both in the alcohol-fixed Papanicolaou and air-dried Romanowsky-stained preparations. IHC, flow cytometric, and cytogenetic studies are critical in establishing the diagnosis of lymphoma and in establishing a definitive classification.

Sarcomas are a very unusual source for MUP, as the primary malignancy is often usually obvious. Whenever a metastatic sarcoma is considered, the more likely diagnosis is a metastatic sarcomatoid carcinoma or melanoma. In the unusual circumstance of a metastatic sarcoma accounting for an MUP, the correct diagnosis can be especially challenging, as sarcomas can have a variety of different patterns including the presence of spindle cells, epithelioid cells, pleomorphic cells, and small cells. A myxoid/chondromyxoid or fibrotic background can be present in some of the cases.

If one cannot place the malignancy into a specific histologic lineage, then an attempt should be made to place it into one of the six morphologic cell patterns (Fig. 4). The "small blue round cell tumor" (SBRCT) category has typically included a variety of malignancies that occur especially in the pediatric age group, but they can also be seen in the adult population (Table 5) [27]. Typically, these malignancies are characterized by a population of relatively small cells having high nuclear-to-cytoplasmic (N/C) ratios. They fall in the small round blue cell category, and include the following: (1) neuroendocrine tumors such as welldifferentiated neuroendocrine neoplasms (carcinoid and islet cell tumors) and poorly differentiated neuroendocrine carcinoma (small cell carcinoma); (2) some poorly differentiated non-small cell carcinomas consisting of relatively small malignant cells such as some basaloid squamous cell carcinomas (Fig. 1) and, less frequently, adenocarcinomas; (3) lymphomas and other hematopoietic malignancies; (4) small round blue cell tumors of childhood; (5) occasional sarcomas such as the small cell variant of synovial sarcoma; and (6) the small cell variant of melanoma. Other malignancies that may be considered within the SRCT categories include lobular carcinoma of the breast, plasmacytomas, and granulosa cell tumor of the ovary. When entertaining the diagnosis of one of the SRCTs of childhood, the following entities are included: Ewing sarcoma, rhabdomyosarcoma, Wilm's tumor, neuroblastoma, and lymphoma. In the work-up of SBRCT, IHC and molecular studies are invaluable [27].

The well-differentiated neuroendocrine neoplasms (carcinoid and islet cell tumors) can show a variety of patterns, in both tissue sections and in the cytologic smears, consisting of granular cytoplasm and eccentrically placed 
Table 5 Morphologic cell patterns and associated primary sites

\begin{tabular}{ll}
\hline Morphologic pattern & Possible primary sites \\
\hline Small cell & $\begin{array}{l}\text { SBRCT, neuroendocrine tumors, PD/basaloid squamous carcinoma, PD } \\
\text { adenocarcinoma, lobular carcinoma, lymphoma, sarcoma, melanoma }\end{array}$ \\
Oncocytic/Granular & $\begin{array}{l}\text { Kidney, liver, salivary gland, thyroid, breast, neuroendocrine tumors, melanoma } \\
\text { Kidney, ovary, liver, adrenal, salivary gland, lung, GYN, thyroid, sarcoma, } \\
\text { Clear cell }\end{array}$ \\
germ cell tumor, chordoma \\
PD carcinoma (lung, pancreas, thyroid, liver), sarcoma, choriocarcinoma, \\
pheochromocytoma, Hodgkin lymphoma, anaplastic large cell lymphoma, \\
melanoma \\
Sarcoma, spindle squamous carcinoma, sarcomatoid carcinoma (kidney, \\
thyroid, lung, pancreas), neuroendocrine tumors, melanoma, lymphoma \\
PD cell
\end{tabular}

GIT gastrointestinal tract, $G Y N$ gynecologic, $P D$ poorly differentiated, $S B R C T$ small blue round cell tumors nuclei, possessing the characteristic salt-and-pepper-type of chromatin. In Romanowsky smears, one can appreciate a "plasmacytoid" appearance of the cells. In contrast, small cell carcinoma consists of small atypical cells having very high N/C ratios with nuclear irregularity and molding [2]. Again, the nuclei have a salt-and-pepper-type chromatin distribution and lack prominent nucleoli. If prominent nucleoli are appreciated, a diagnosis other than a small cell carcinoma should be seriously considered. Due to the nuclear fragility of the cells, DNA streaking can be appreciated, both in the tissue sections and the cytologic smears and crush artifact with loss of nuclear detail is not uncommon. In histologic sections, "Azzopardi" effect, characterized by DNA encrustation of intratumoral blood vessels, can be present. A potential pitfall for a falsepositive diagnosis of a small cell carcinoma is an aspirate of an adrenal cortical nodule in a patient presenting with a lung nodule. An aspirate of an adrenocortical nodule can consist of stripped nuclei, due to the fragility of the adrenocortical cells that can simulate a metastatic small cell carcinoma, especially if the patient also has a lung nodule. Close attention to the nuclear detail can prevent this mistake.

Tumors that fall into the pleomorphic/giant cell category typically have very atypical large, round to polygonal cells with multinucleation and/or spindle cells not uncommonly seen (Table 5). A variety of carcinomas, lymphomas, germ cell malignancies, endocrine carcinomas, and melanomas fall into this category. In this setting, IHC can be of considerable value in establishing the correct diagnosis.

In the malignant spindle cell category, the following entities should be considered: spindle cell sarcomas, peripheral neuroectodermal tumors, gastrointestinal stromal tumors, sarcomatoid carcinomas such as sarcomatoid squamous cell carcinoma, endocrine tumors such as an occasional paragangliomas, pseudosarcomas such as nodular fasciitis, fibromatosis and mesenchymal repair, and melanoma [21, 23] (Table 5). The evaluation of a spindle cell neoplasm is greatly influenced by the site of involvement. A malignant spindle cell lesion of the soft tissue would most likely be a sarcoma, although metastatic spindle cell carcinomas or melanomas can also involve the soft tissue. A helpful feature to separate a spindle cell type of carcinoma from a sarcoma and melanoma is the dissociative pattern of the cells in sarcoma or metastatic melanoma. Again, in the work-up of spindle cell lesions of unknown primary, immunohistochemical evaluation is critical. An initial immunohistochemical panel consisting of S-100, Sox 10, melanoma cocktail, HMB 45, etc., for melanoma, and a variety of cytokeratins for carcinoma and specific immunohistochemical markers for soft tissue lesions are recommended.

Neoplasms with abundant eosinophilic, oncocytic, or granular cytoplasm include the following: (1) adenomas and carcinomas that can involve the liver, salivary gland, cervix (glassy cell); (2) oncocytic/Hürthle cell neoplasms of the kidney and thyroid, etc.; (3) neoplasms of apocrine derivation from the breast, sweat glands, and skin; (4) endocrine tumors such as carcinoid and paragangliomas; (5) soft tissue tumors such as granular cell tumor and alveolar soft part sarcoma; and (6) melanoma (Table 5). Cytoplasmic granularity can be due to a variety of different factors, including increased numbers of intracytoplasmic mitochondria, smooth endoplasmic reticulum, lysosome-like bodies, secretory granules, and neuroendocrine-type granules. In evaluation of these neoplasms, IHC can be of considerable help.

In the clear cell category, a variety of carcinomas need to be considered, but the prototypical clear cell malignancy accounting for MUP is the conventional renal cell carcinoma (Fig. 2), followed by malignancies of the ovary, liver, adrenal and salivary glands, lung, gynecologic, and thyroid origin $[21,23]$. Other types of clear cell neoplasms include oncocytic neoplasms with clear cell change, acinar cell tumors, neuroendocrine tumors such as paraganglioma, soft tissue neoplasms such as clear cell sarcoma, and some germ 


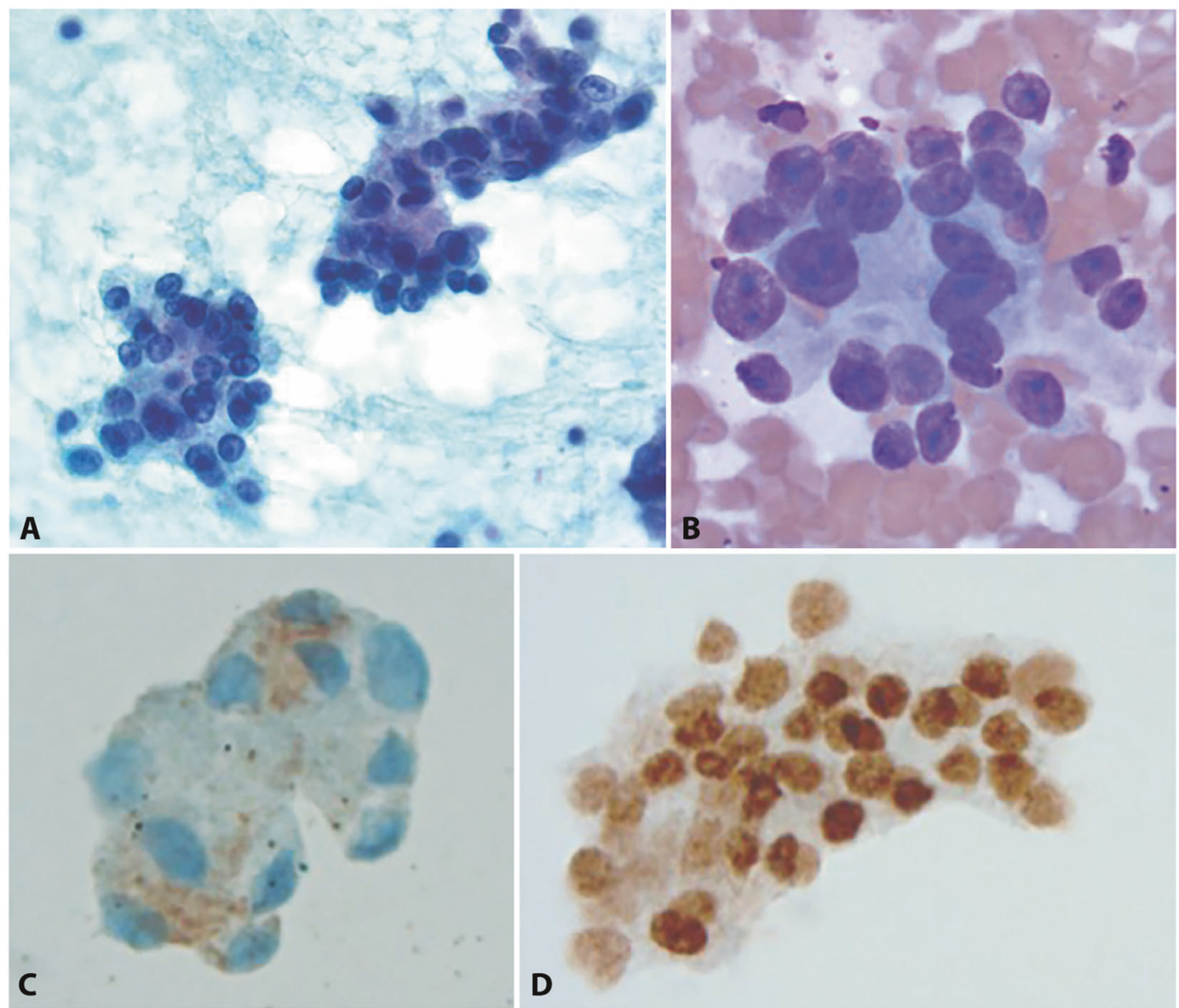

Fig. 5 Metastatic prostatic adenocarcinoma. Fine needle aspiration biopsy of a lung nodule from a 76 year old man, with no previous history of malignancy. a, b The smears showed a predominant microacinar configuration, moderate sized cells with round nuclei and prominent nucleoli (a Papanicolaou stain; b Diff Quik stain).

cell tumors. Melanoma can also rarely have clear cells (balloon cells) (Table 5).

MUPs having a large cell polygonal appearance may present as cohesive clusters or single cells/dissociative pattern. The malignant cells are characterized by intermediate sized round to polygonal shaped cells with abundant cytoplasm and variable atypia [24]. When predominately cohesive, differential diagnosis includes poorly differentiated carcinoma (squamous, adenocarcinoma, urothelial), neuroendocrine carcinoma (large cell neuroendocrine, medullary), melanoma, and anaplastic large cell lymphoma. If predominately discohesive in pattern, most common primaries include pancreas and stomach (undifferentiated/signet ring carcinoma) and breast (ductal, pleomorphic lobular). Other possible primaries include neuroendocrine neoplasms, hematopoietic malignancies, sarcoma, and melanoma [24].

If one cannot still slot the tumors into a specific histologic lineage or morphologic cell pattern, then secondary features may be helpful in arriving at the correct diagnosis c, d There was positive staining with prostatic specific membrane antigen (PSMA) and NKX3.1. There was negative staining with prostatic specific antigen (PSA) and prostate acid phosphatase (PAP) (not shown). NKX3.1 is currently considered the most sensitive prostatic marker in the work-up of metastatic malignancies

[2]. Secondary patterns include the presence of intranuclear cytoplasmic inclusions, which can be typically seen in papillary carcinoma of the thyroid and occasional hepatocellular carcinoma and melanomas. The presence of microacinar complexes should raise the possibility of a metastasis of prostate (Fig. 5), thyroid or well-differentiated neuroendocrine neoplasm. Utilization of IHC can usually lead to a more specific diagnosis in those instances. Malignancies with a mucinous background include colloid carcinomas of gastrointestinal, breast, ovarian, or pancreatic origin. Also, to be considered are some myxoid sarcomas.

Malignancies with a plasmacytoid cell pattern include plasma cell neoplasms, well-differentiated neuroendocrine neoplasms, melanoma, breast carcinoma, and primary pleomorphic adenomas. Tumor cells having a linear arrangement include metastases from well-differentiated neuroendocrine carcinomas and breast (especially lobular carcinoma). Malignancies with intracytoplasmic hyaline globules can be seen in a variety of carcinomas, sarcomas, lymphomas, germ cell neoplasms, and melanoma. When 
Table 6 IHC work-up of differentiated malignancy undifferentiated/poorly

\begin{tabular}{llllll}
\hline & AE-1/3 & CD 45 & S-100 & PLAP & Additional markers \\
\hline Carcinoma & + & - & \pm & - & Differential keratins and non-keratins, i.e., CK7/20, \\
Melanoma & - & - & + & - & HMB 45, Melan A, SOX10, etc. \\
Lymphoma & - & + & - & - & CD3, CD20, CD30, etc. \\
Germ cell tumor & \pm & - & - & + & SALL4, CD30, OCT4, etc. \\
\hline
\end{tabular}

Table 7 Differential keratins and organ-specific and -associated immunohistochemical markers

\begin{tabular}{|c|c|c|}
\hline CK7/CK20 profiles & $\begin{array}{l}\text { Nuclear transcription } \\
\text { factors }\end{array}$ & Organ-associated markers \\
\hline $\begin{array}{l}-C K 7+/ C K 20-: \text { most adenocarcinomas } \\
\cdot C K 7-/ C K 20-: \text { renal, prostate, adrenal, } \\
\text { most squamous cell, hepatocellular } \\
\cdot C K 7-/ C K 20+: \text { colorectal, Merkel cell } \\
\cdot C K 7+/ C K 20+: \text { urothelial, upper GI, } \\
\text { pancreas/biliary, mucinous ovarian }\end{array}$ & $\begin{array}{l}\text {-TTF1: lung and thyroid } \\
\text {-CDX2, SATB2: colorectal, } \\
\text { biliary, pancreas } \\
\text {-NKX3.1: prostate } \\
\text {-GATA3: breast, urothelial } \\
\text {-MITF/SOX10: melanoma } \\
\text {-WT1: serous CA, } \\
\text { mesothelial } \\
\text {-Pax8: mullerian, thyroid, } \\
\text { renal } \\
\text {-MyoD1, myogenin: } \\
\text { skeletal muscle }\end{array}$ & $\begin{array}{l}\text {-PSA and PSAP: prostate } \\
\text {-Thyroglobulin: thyroid } \\
\text {-Uroplakin: urothelial } \\
\text {-Inhibin: adrenal, sex cord/ } \\
\text { stromal, granulosa cell } \\
\text {-Hep Par-1, Glypican3: } \\
\text { hepatocellular } \\
\text {-Napsin A: lung, renal } \\
\text {-ER/PR: breast, GYN } \\
\text {-RCC antigen: renal }\end{array}$ \\
\hline
\end{tabular}

$E R / P R$ estrogen receptor/progesterone receptor, $G I$ gastrointestinal present in carcinoma, diagnostic considerations should include hepatocellular carcinoma, renal cell carcinoma, germ cell malignancies, and ovarian carcinoma. When the intracytoplasmic globules are eosinophilic and large, and the cells have eccentric nuclei with prominent nucleoli, then a rhabdoid phenotype is appreciated. Malignancies with rhabdoid phenotypes usually are poorly differentiated and aggressive. The most common metastatic malignancy having a rhabdoid phenotype is metastatic melanomas $[13,23,28,29]$.

\section{Immunohistochemistry}

Ancillary studies are frequently used when evaluating CNB and cell block from FNA specimens to determine the primary site of an MUP. One must be aware, however, that there is no single immunohistochemical antibody that can provide a definitive diagnosis in most cases [26]; therefore, a panel of immunohistochemical stains should be utilized [25]. We recommend that an algorithmic, interpretative approach be utilized in ordering and evaluating immunohistochemical stains [5, 30-32]. The immunohistochemical work-up of an undifferentiated/ poorly differentiated malignancy can be initially done using IHC stains that can slot the malignancy into carcinoma, melanoma, lymphoma or germ cell categories (Table 6) [1]. In the work-up of an adenocarcinoma, IHC stains for cytokeratins 7 and 20 can help characterize most carcinomas (Table 7). Our ability to further make a specific diagnosis has been helped with the advent of the ever-increasing number of nuclear transcription factor antibodies and organ-specific immunohistochemical markers (Table 7) (Figs. 5, 6) [25, 32]. Having said that, thoughtful ordering of IHC stains is critical to optimize the specimen. The pathologist must try to ensure that there is sufficient material also available for molecular studies in the cell block and/or CNB. In FNA cytology, we always attempt to obtain a cell block for these studies and order unstained sections upfront in order to best conserve a limited specimen for ancillary studies. If there is not sufficient material in the cell block or the CNB, a novel cell transfer technique (CTT) [33] can be extremely helpful and is further discussed below.

\section{Cell transfer technique}

We have utilized the CTT at our institutions with great success and have mainly used it on FNAs and exfoliative cytology specimens that had limited number of diagnostic slides and/or lacked adequate cellularity of the cell block to allow for further ancillary testing [33]. CTT is a simple procedure and requires minimal equipment and supplies (Table 8). Our methodology is very similar to that described by Gong et al. [34], which is also recommended by the manufacturer of "Mount Quick Medium" (New Comer Supply; Middleton, WI). Multiple IHC stains can be applied to a single cytologic preparation or histologic slide (Fig. 7). In our experience, the best IHC results were achieved on cell-transferred pieces obtained from alcohol-fixed 


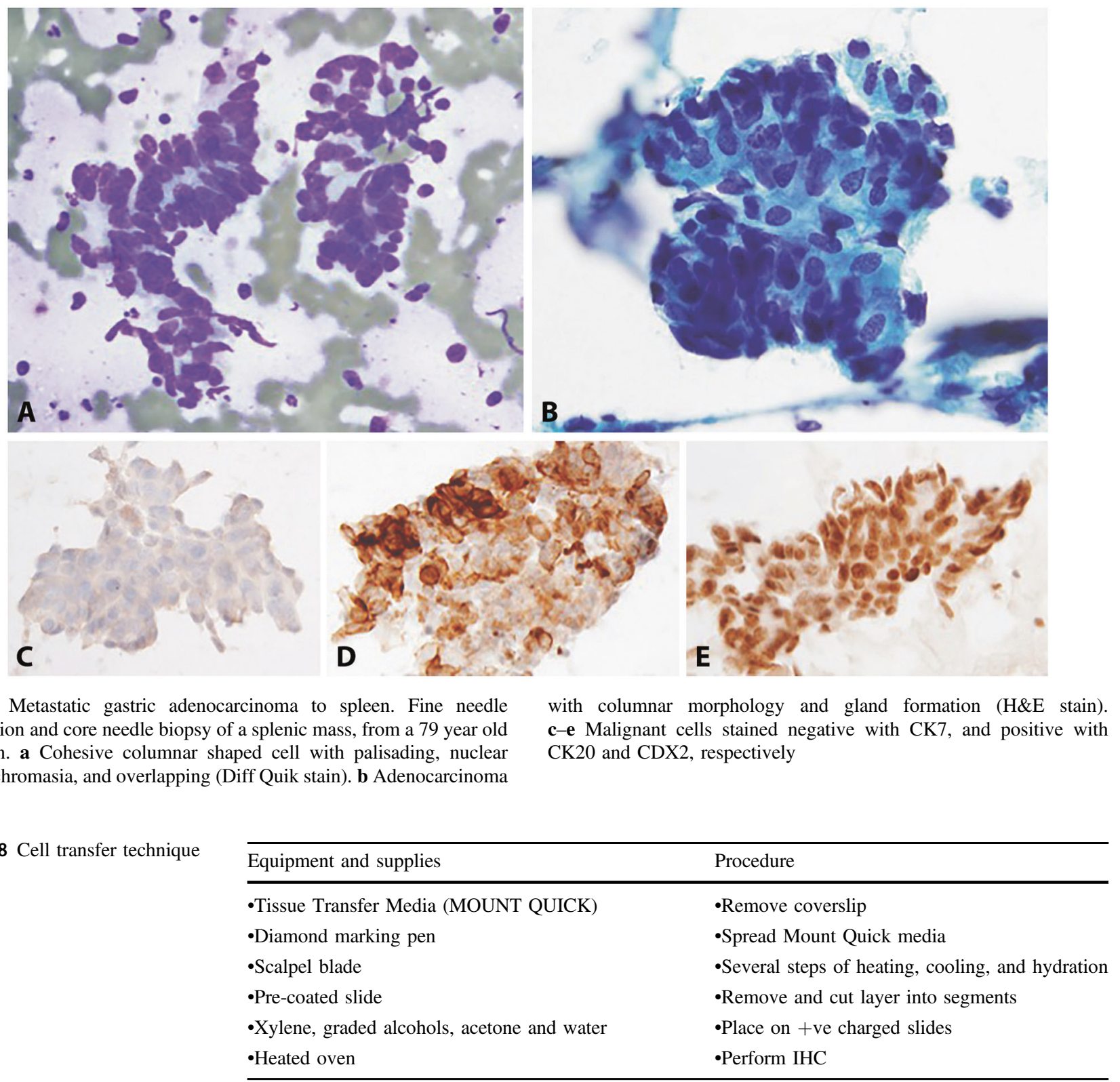

cytologic smears, treated with antigen retrieval, and not subjected to destaining [33].

Figure 8 demonstrates an example of a case where CTT was crucial in establishing a specific diagnosis and prevented the need for a repeat biopsy. A 60-year-old male patient presented with a lung mass and paratracheal lymphadenopathy, status post radical cystectomy, and chemotherapy since 3 years. Clinical differential diagnosis was a second primary lung carcinoma vs. metastatic urothelial carcinoma. Endobronchial ultrasound (EBUS)-guided FNA of the paratracheal lymph node showed high-grade nonsmall cell carcinoma, but cytology alone could not determine whether this represented a primary or metastatic malignancy. The cell block was acellular, so we performed a panel of six IHC stains, utilizing the CTT, on a single alcohol-fixed smear (Fig. 8). The malignant cells stained positive with CK7, CK20, p63, and GAT3, consistent with metastatic urothelial carcinoma.

A recent study showed that although CTT was used in only $1.4 \%$ of their FNA cases, it contributed to the final diagnosis in $79 \%$ of the cases in which it was used [35]. For these patients, CTT reduced the need for repeat biopsies, therefore reducing potential patient morbidity and additional health care costs. Molecular testing performed on H\&E-stained sections via CTT has also been utilized when tissue from cell blocks and small surgical biopsy samples were exhausted and the only available material for testing was present on the H\&E-stained slides. Wu et al. [36] applied PCR-based molecular testing (EGFR, BRAF, KRAS) using CTT on 97 samples, with $85 \%$ success rate, 

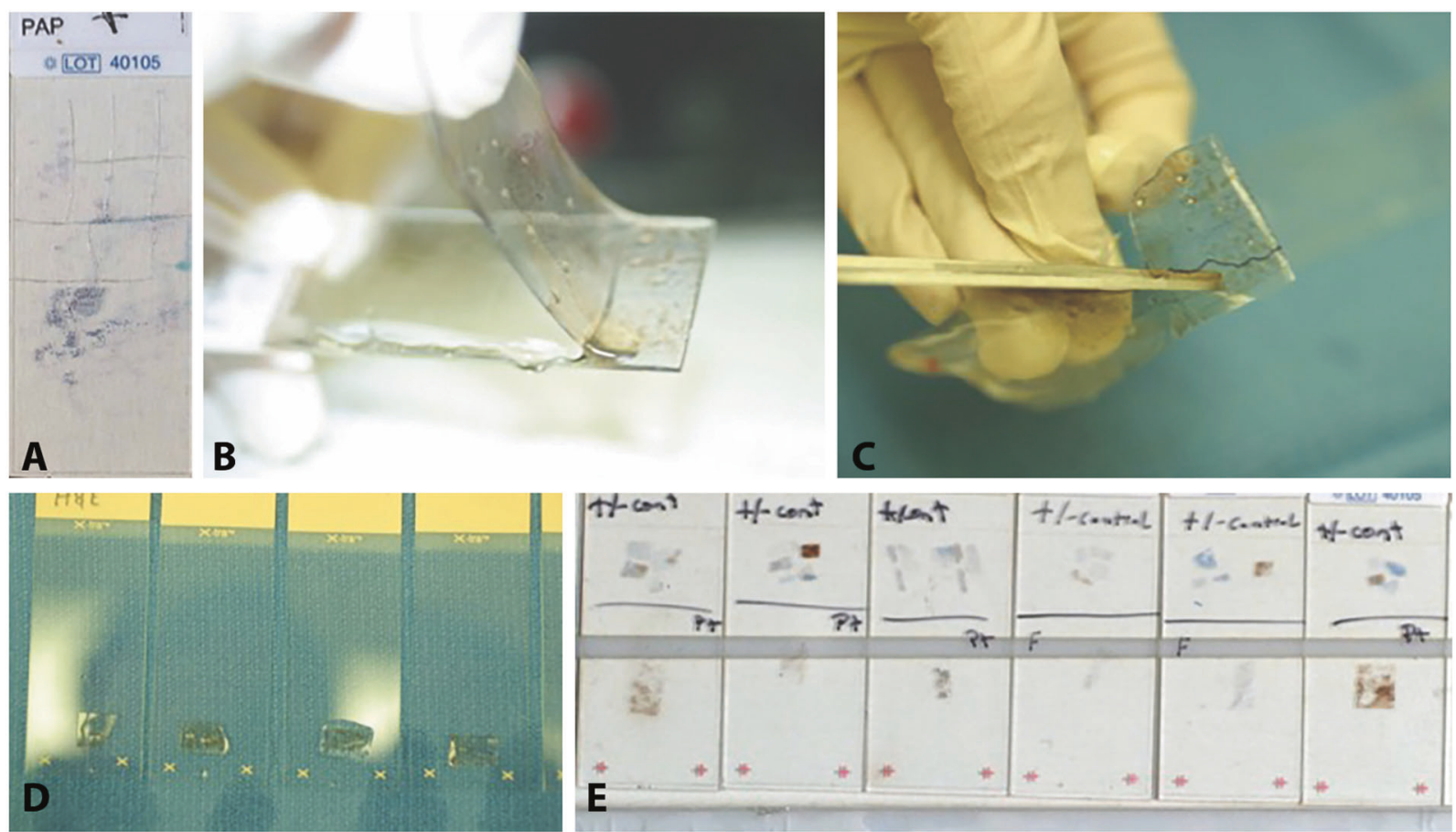

Fig. 7 Cell transfer technique (CTT). CTT is a simple procedure and can usually be completed within $24-48 \mathrm{~h}$. a After removing the coverslip, Mount Quick media is spread on the slide, then subjected to several steps of heating, cooling, and hydration (not shown). b An intact layer, containing the cells, is peeled off the slide. $\mathbf{c}$ The layer is removed and cut into smaller segments. d These smaller segments are placed on positively charged slides. e Immunohistochemistry is performed on those slides with standard procedure
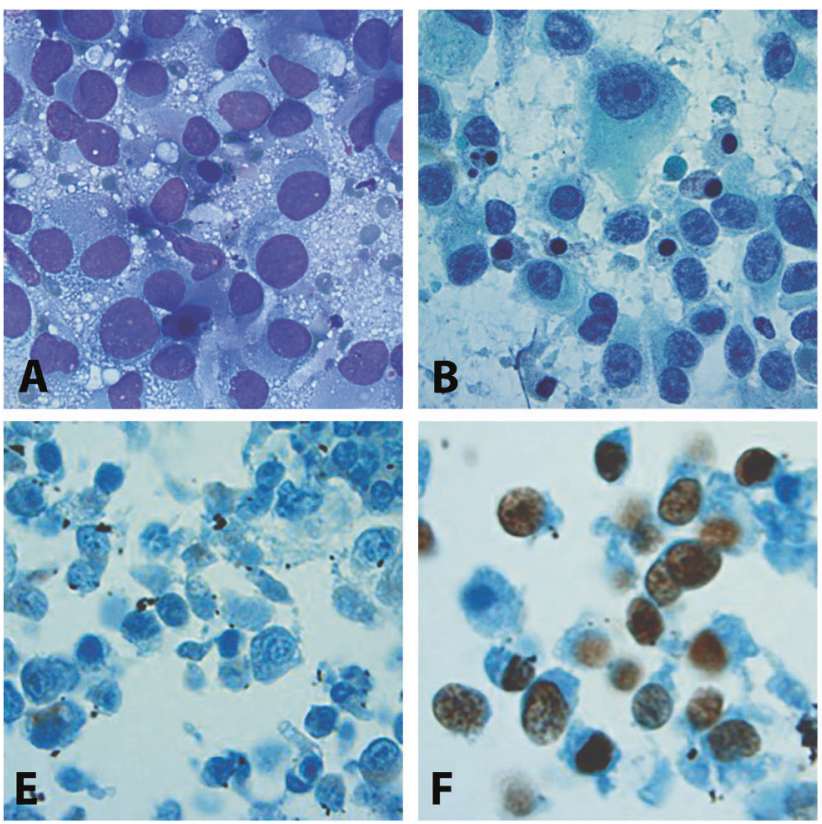

Fig. 8 Metastatic urothelial carcinoma diagnosed utilizing cell transfer technique (CTT). a, b Cytology showed large polygonal cells with variable atypia, mostly in a dyscohesive pattern (Diff Quik and Papanicolaou stains, respectively). c-e Differential keratins showed

and established $99 \%$ concordance of results with previous standard methods. IHC performed on cell-transferred material, in our experience, is very accurate and has

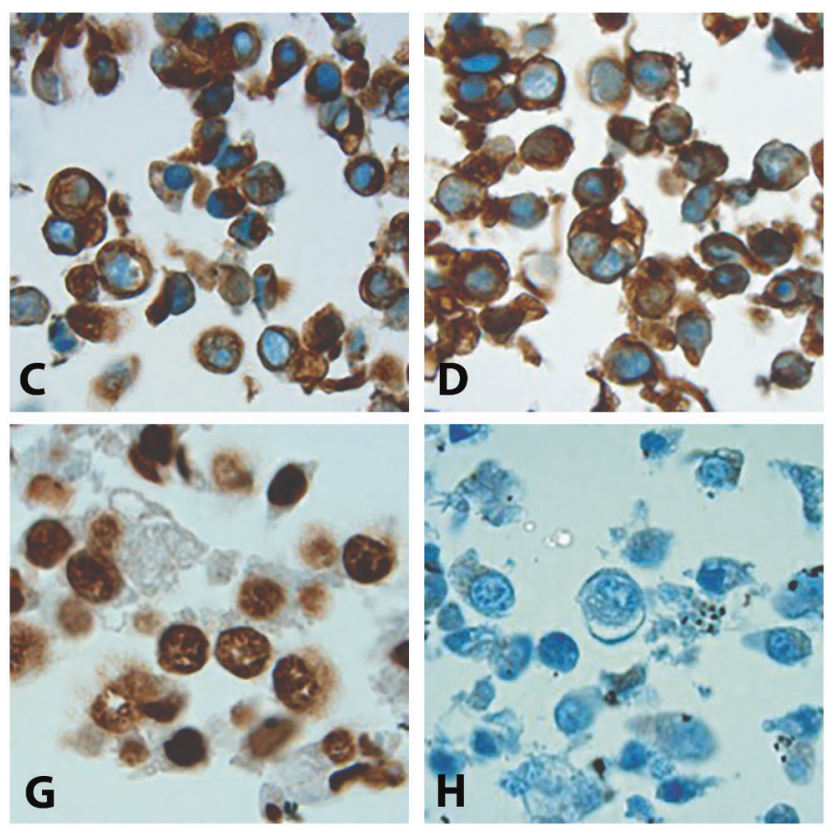

positive staining with CK7 and CK20, and negative staining with CK5/6. f, g Strong positive nuclear staining with p63 and GAT3. h Negative staining with TTF1

comparable results to those performed on formalin fixed tissue. We have also applied CTT to ThinPrep slides, and H\&E-stained sections from cell blocks and CNB's that had 
Table 9 Molecular testing in metastases of unknown primary origin (common commercial tests)

\begin{tabular}{ll}
\hline Molecular test & Type of assay \\
\hline 1.CancerType ID ${ }^{\circ}$ (BioTheranostics) & GEP \\
2.Tissue of Origin Test (Cancer Genetics) & GEP \\
3.Rosetta Cancer Origin Test (Rosetta Genomics) & GEP \\
4.Caris Molecular Intelligence (Caris Life Sciences) & Multiple tumor profiles, including IHC, ISH, NGS \\
5.Foundation One (Roche Foundation Medicine) & NGS \\
6.Oncofocus (Oncologica UK) & NGS \\
\hline
\end{tabular}

GEP gene expression profiling, $I H C$ immunohistochemistry, $I S H$ in-situ hybridization, $N G S$ next-generation sequencing no significant residual tissue in the paraffin block for ancillary testing, with similar success.

\section{Molecular testing}

More recently, molecular testing has been utilized in the evaluation of MUPs, to identify the primary site of origin, or detect a genetic mutation. Molecular testing has mostly employed gene expression profiling (GEP) and nextgeneration sequencing platforms (NGS). In GEP, there are a number of different techniques available, but they generally attempt to identify the primary site by profiling genetic signatures of the MUP and matching it to a database of known primaries. The NGS platforms are designed to detect actionable mutations in cancer genes that can be targeted with on-market oncologic drugs or treatments in clinical trials. There are a number of commercial tests available, most common of which are outlined in Table 9. However, a number of questions still remain concerning the cost effectiveness and accuracy of these molecular tests and their benefit apart from traditional clinical and pathologic evaluations.

GEP has shown high agreement with already available clinicopathologic data, including clinical history, physical exam, laboratory and imaging results, histologic/cytologic examination, and IHC. Sensitivity/agreement is reported to be in the range of $72-95 \%[6,37,38]$. As GEP is associated with high cost $(\$ 2,000-\$ 5,000)$, we believe it is best used as a complimentary test in MUP cases unresolved by clinicopathologic data. Another question is whether MUP with molecular signature of a specific primary responds similar to treatment given to metastasis from a known primary? Clinical trials are currently underway to assess the efficacy of molecular profiling-based treatment in MUP and hope to shed some light on this issue.

NGS detects potentially actionable genes in up to $85 \%$ of MUPs and theoretically the detected mutations would be amenable to targeted therapy [6, 37]. It is currently unclear, however, if targeted therapy improves patient prognosis in the setting of MUP, and if NGS is cost effective (cost ranges from \$2000-\$4000). Therefore, prospective randomized trials are needed to better determine which genes are truly actionable, and if targeted therapy improves prognosis of MUP patients, and if it is more important to identify the MUP primary site or detect an actionable gene? [25] There is no question, however, that the future is promising for molecular testing, as additional genes are detected and better determinations of best profiling methodology and gene panels are made.

\section{Summary}

In summary, determining an accurate diagnosis of MUP is only one component in the work-up of the patient. There is currently available data to suggest that there is a management benefit in identifying the primary site [2]. Preservation of limited diagnostic material for potential ancillary and molecular studies is critical. When preforming ancillary studies, an algorithmic approach is recommended, and correlation of the clinical, morphologic, and ancillary studies is needed to establish the correct diagnosis [5, 32]. We believe that the role of on-site evaluation (preliminary interpretation) is extremely important and is the critical step for the appropriate triage of the specimen. When encountering a MUP, appreciation of unusual cytologic appearance for the sampled site may be the first indication that one is dealing with a MUP rather than a primary malignancy. The pathologist's role is to correlate the cytohistologic findings with the clinical information to generate an appropriate differential diagnosis and then utilize an appropriate limited immunohistochemical panel to help determine the primary site. When one does not have sufficient material in the cell block and/or core biopsy, the CTT may be utilized. We believe that currently genomics/molecular testing can have a complementary role in specific cases but has a promising future, especially in the area of targeted therapy.

\section{Compliance with ethical standards}

Conflict of interest The authors declare that they have no conflict of interest. 


\section{References}

1. Kandukuri SR, Lin F, Gui L, et al. Application of immunohistochemistry in undifferentiated neoplasms: a practical approach. Arch Pathol Lab Med. 2017;141:1014-32.

2. Elsheikh TM, Silverman JF. Metastatic malignancies. In: Wick Meditor. Principles and Practice of Surgical Pathology and Cytopathology. 5th edn. p. 255-290, United Kingdom: Cambridge Univ. Press; 2014.

3. Elsheikh TM, Silverman JF. Fine needle aspiration cytology of metastasis to common and unusual sites. Path Case Rev. 2001; 6:161-72.

4. Haskell CM, Cochran AJ, Barsky SH, Steckel RJ. Metastasis of unknown origin. Curr Probl Cancer. 1988;12:5-58.

5. Kandalaft PL, Gown AM. Practical applications in immunohistochemistry: carcinomas of unknown primary site. Arch Pathol Lab Med. 2016;140:508-23.

6. Tomuleasa C, Zaharie F, Muresan MS, et al. How to diagnose and treat a cancer of unknown primary site. J Gastrointestin Liver Dis. 2017;26:69-79.

7. Greco FA, Vaughn WK, Hainsworth JD. Advanced poorly differentiated carcinoma of unknown primary site: recognition of a treatable syndrome. Ann Intern Med. 1986;104:547-53.

8. Kambhu SA, Kelsen DP, Fiore J, et al. Metastatic adenocarcinomas of unknown primary site. Prognostic variables and treatment results. Am J Clin Oncol. 1990;13:55-60.

9. Neumann KH, Nystrom JS. Metastatic cancer of unknown origin: nonsquamous cell type. Semin Oncol. 1982;9:427-34.

10. Pasterz R, Savaraj N, Burgess M. Prognostic factors in metastatic carcinoma of unknown primary. J Clin Oncol. 1986; 4:1652-7.

11. Sporn JR, Greenberg BR. Empiric chemotherapy in patients with carcinoma of unknown primary site. Am J Med. 1990;88:49-55.

12. Schlag PM, Hunerbein M. Cancer of unknown primary site. Ann Chir Gynaecol. 1994;83:8-12.

13. Lembersky BC. Metastatic malignancies of unknown primary: the medical oncolgist's pont of view. Path Case Rev. 2001;6: 178-84.

14. Varadhachary GR, Lenzi R, Raper MN, Abbruzzese JL. Carcinoma of unknown primary. In: Abeloff's Clinical oncology. 5th edn. p. 792-803, Elevier Churchil Livingston. 2014.

15. Brown RW, Campagna LB, Dunn JK, Cagle PT. Immunohistochemical identification of tumor markers in metastatic adenocarcinoma. A diagnostic adjunct in the determination of primary site. Am J Clin Pathol. 1997;107:12-9.

16. Gamble AR, Bell JA, Ronan JE, Pearson D, Ellis IO. Use of tumour marker immunoreactivity to identify primary site of metastatic cancer. BMJ. 1993;306:295-8.

17. Wick MR, Ritter JH, Swanson PE. The impact of diagnostic immunohistochemistry on patient outcomes. Clin Lab Med. 1999; 19:797-814. vi

18. Elsheikh TM, Herzberg AJ, Silverman JF. Fine-needle aspiration cytology of metastatic malignancies involving unusual sites. Am J Clin Pathol. 1997;108:S12-21.

19. Gilbert HA, Kagan AR, Rao A, Nussbaum H, Hintz B, Chan PYM. Considerations in the Evaluation of Cancer Metastases to Visceral Organs. In: Grundman E, editor. Metastatic Tumor Growth. 222-225, Stuttgart New York: Gustav Fisher Verlag; 1980.
20. Molinari R, Cantu G, Chiesa F, et al. A statistical approach to detection of the primary cancer based on the site of neck lymph node metastases. Tumori J. 1977;63:267-82.

21. DeMay R. The art and science of cytopathology. Chicago, Illinois: ASCP Press; 2011.

22. Cerilli LA, Wick MR. Metastatic malignancies of unknown origin: a histologic and cytologic approach to diagnosis. Pathol Case Rev. 2001;6:137-45.

23. Green LK, Ro JY, Mackay B, Ayala AG, Luna MA. Renal cell carcinoma metastatic to the thyroid. Cancer. 1989;63:1810-5.

24. Elsheikh TM. Fine needle aspiration cytology of tumors of unknown origin. In: Gatttuso P, Reddy VB, Masood D, editors. Differential diagnosis in cytopathology. 2 edn. p. 640-665, United Kingdom: Cambridge Univ. Press; 2015.

25. Monaco SE, Dabbs DJ. Metastatic Tumors of Unknown Origin: Ancillary Testing in Cytologic Specimens. Surg Pathol Clin. 2014;7:105-29.

26. Slagel DD, Raab SS, Silverman JF. Fine needle aspiration biopsy of metastatic malignant melanoma with "rhabdoid" features. Freq, Cytol Features, pitfalls Ancillary Stud Acta Cytol. 1997;41: 1426-30.

27. Geisinger K, Silverman J, Wakely P Jr. Pediatric cytopathology. In: ASCP Theory and practice of cytopathology. p. 265-353, Chicago: American Society of Clinical Pathologists; 1994.

28. Sidawy MK, Bosman FT, Orenstein JM, Silverberg SG. Differential diagnosis of metastatic tumors. In: Principles and practice of surgical pathology and cytopathology. 3rd edn. p. 303-326, New York: Churchill Livingstone; 1997.

29. Lioe TF, Elliott H, Allen DC, Spence RA. The role of fine needle aspiration cytology (FNAC) in the investigation of superficial lymphadenopathy; uses and limitations of the technique. Cytopathology. 1999;10:291-7.

30. Dabbs DJ, Silverman JF. Immunohistochemical workup of metastatic carcinoma of unknown primary. Pathol Case Rev. 2001;6:146-53.

31. DeYoung BR, Wick MR. Immunohistologic evaluation of metastatic carcinomas of unknown origin: an algorithmic approach. Semin Diagn Pathol. 2000;17:184-93.

32. Stelow EB, Yaziji H. Immunohistochemistry, carcinomas of unknown primary, and incidence rates. Semin Diagn Pathol. 2018; $35: 143-52$

33. Elsheikh TM, Corbin K. Validation of commonly used immunostains on cell-transferred cytologic specimens. Cancer. 2006; 108:135-6. author reply 6

34. Gong Y, Joseph T, Sneige N. Validation of commonly used immunostains on cell-transferred cytologic specimens. Cancer. 2005;105:158-64.

35. Marshall AE, Cramer HM, Wu HH. The usefulness of the cell transfer technique for immunocytochemistry of fine-needle aspirates. Cancer Cytopathol. 2014;122:898-902.

36. Wu HH, Jovonovich SM, Randolph M, et al. Utilization of celltransfer technique for molecular testing on hematoxylin-eosinstained sections: a viable option for small biopsies that lack tumor tissues in paraffin block. Arch Pathol Lab Med. 2016;140:1383-9.

37. Perone Y, Fioretti FM. Journal club: epigenetic profiling to classify cancer of unknown primary. Lancet Oncol. 2017;18:e130.

38. Oien KA, Evans TR. Raising the profile of cancer of unknown primary. J Clin Oncol. 2008;26:4373-5. 